\title{
OVIPOSITION PREFERENCE HIERARCHY IN CERATITIS CAPITATA (DIPTERA, TEPHRITIDAE): INFLUENCE OF FEMALE AGE AND EXPERIENCE
}

\author{
Iara S. Joachim-Bravo ${ }^{1}$ \\ Odair A. Fernandes ${ }^{2}$ \\ Sérgio A. Bortoli \\ Fernando S. Zucoloto ${ }^{3}$
}

\begin{abstract}
The influence of two factors, age and previous experience, on the oviposition hierarchy preference of Ceratitis capitata (Wiedemann, 1824) females was studied. Two populations were analyzed: one reared in laboratory during 17 years and the other captured in nature. In the first experiment the oviposition preference for four fruits, papaya, orange, banana and apple was tested at the beginning of oviposition period and 20 days past. The results showed that the wild females as much the laboratory ones had an oviposition preference hierarchy at the beginning of peak period of oviposition. However this hierarchic preference disappeared in a later phase of life. In the second experiment the females were previously exposed to fruits of different hierarchic positions and afterwards their choice was tested in respect to the oviposition preference for those fruits. The results showed that there was an influence of the previous experience on the posterior choice of fruits to oviposition when the females were exposed to fruits of lower hierarchic position.
\end{abstract}

KEYWORDS. Medfly, hosts, behavior, oviposition, Ceratitis.

\section{INTRODUCTION}

The oviposition behavior in insects has been a highly studied theme in the insectplant interaction context. That behavior is connected to the causes for insect's specificity to determined host plants, to the origin of the host changes and to the insect-plant coevolution (Thompson \& Pellmyr, 1991). In holometabolous insects the oviposition behavior is decisive in the choice of proper host plant to the immature, once they have relatively little mobility and depend on the nutritional resources selected by the adult females for their survival (Singer, 1986; Renwick, 1989). How the females find and select the proper host to oviposition is a quite complex question. A conjugation of plant physical and chemical factors influences on that choice and the balance between positive and negative stimuli determines the final selection (EISEMAnN \& Rice, 1985; McInnis, 1989; Oi \& Mau, 1989; Messina, 1990; Kostal, 1993).

The existence of a hierarchy in preference for host in polyphagous phytophagous species has been shown (THOMPSON, 1988). Although a change in the hierarchy is difficult to occur, it can be modified by the influence of the previous experience, which is the preference of the females for host plants they had already had a previous contact with, during a certain period (CoOley et al., 1986; Papaj \& Prokopy, 1986; HoffMann, 1988). In

\footnotetext{
1. Departamento de Biologia Geral, Instituto de Biologia, Universidade Federal da Bahia, Campus Universitário de Ondina, Rua Barão do Geremoabo s/n, 40170-290, Salvador, Bahia, Brasil. (ibravo@ufba.br)

2. Departamento de Entomologia e Nematologia, Faculdade de Ciências Agrárias e Veterinárias, Universidade Estadual Paulista, Rodovia Carlos Tonanni km 5, 14870-000, Jaboticabal, São Paulo, Brasil.

3. Departamento de Biologia, Faculdade de Filosofia, Ciências e Letras de Ribeirão Preto, Universidade de São Paulo, Avenida Bandeirantes, 3900, 14040-901, Ribeirão Preto, São Paulo, Brasil. (zucoloto@ffclrp.usp.br).
} 
the lack of a preferable host, the females may also lay eggs on hosts of lower hierarchy (SINGER, 1986). Some authors infer yet that the female age is an important factor in the hierarchic change (COURTNEY et al., 1989).

The species Ceratitis capitata (Wiedmann, 1824) is a multivoltinuous and a polyphagous one. In Brazil it is found specially in the south and south-east regions and can infest about 200 species of commercial and non-commercial fruits (MALAVASI et al., 1980; Martins et al., 1993). About the oviposition behavior of the females it is also pointed out that they make use of smell and visual signs to locate and recognize the oviposition sites and that they prefer to lay eggs on ripe fruits (PROKOPY \& RoITBERG, 1984; OI \& MAU, 1989). Females with previous experience of oviposition have a higher tendency to chose the same fruit to land on and to perforate (РRокору et al., 1989). The females also present a learning ability to recognize the host biotype (COoLEy et al., 1986).

Many aspects of the host plant selection to oviposition among the C. capitata are still poorly known. The objective is to study whether there was or not a hierarchy in the oviposition preference for different commercial hosts by the females of this species and what is the influence on this hierarchic preference of two factors, age and previous experience.

\section{MATERIAL AND METHODS}

The experiments were conducted with two different populations of $C$. capitata. One of these populations comes from a laboratory raising at the Biology Department at the Faculdade de Ciências e Letras de Ribeirão Preto, USP, São Paulo, Brazil. They were about 17 years, about 170 generations, came up from infested peaches. The other population was composed of wild flies collected from orchards in the region of Ribeirão Preto, SP. Both populations were compared in terms of the proposed objectives.

To verify the existence or inexistence of an oviposition hierarchic preference by the females as much the influence of age on this hierarchic preference, four fruits were chosen as hosts: papaya (Carica papaya L.), banana (Musa paradisiaca L.), orange (Citrus sinensis (L.) Osbeck) and apple (Pyrus malus L.). The choice of the fruits for oviposition was based on a former work (Zucoloto, 1993) in which the fruits had a different acceptability by the females when tested individually. The fruits were always bought from the same supermarket in Ribeirão Preto, SP.

In the beginning of the experiment 20 recently emerged couples were set individually in cages $(20 \times 20 \times 20 \mathrm{~cm})$ and fed on a yeast based diet (Boneg, Juiz de Fora, Brazil) - $6.5 \mathrm{~g}$ sucrose - $11.0 \mathrm{~g} / 100 \mathrm{ml}$ diet. When the oviposition peak started, in 7 days for the laboratory and 15 days for the wild females (once the mating and the egg laying begin earlier in flies raised in laboratory), the four fruits were offered simultaneously. The fruits were offered in small pieces $(5.0 \mathrm{~g})$ and placed equidistantly from the others. The pieces were replaced daily by fresh ones and their positions in the cage were changed to avoid a possible interference of the place in the oviposition preference by the females. The experiment was closed after 6 days and the amount of eggs in each fruit was counted. Twenty days after the closing of the first test, the oviposition preference for the fruits was again tested with the same females. The flies that died during the experiment were discarded from the analyses. Many repetitions were proceeded until the sample reached 20 females. The data were analyzed by the Freedman statistic test at a level of 5\% (SIEGEL, 1956).

The second experiment evaluated the influence of the adult previous experience on the oviposition hierarchic preference. The objective here was to evaluate whether the experience with one host of lower hierarchy increased or not the preference for it in relation to another of a higher hierarchy. Three fruits with different hierarchic positions were chosen to this test, based on the results from the experiment about hierarchy in the first part of this work.

Three groups of recently emerged flies (with 30 males and 30 females each) were set in the cage and fed on the diet referred above. In the beginning of the oviposition period, two pieces $(5.0 \mathrm{~g})$ of one of the three tested fruits were given to each of the three groups. After three days of exposure to the fruits, twenty females from each group were tested individually in relation to the oviposition preference between the two fruits. The fruits were tested two by two in simultaneous choice tests, as following: group 1 (exposure to fruit 1), choice tests between fruit 1 and fruit 2 and between fruit 1 and fruit 3; group 2 (exposure to fruit 2), choice tests between fruit 2 and fruit 1 and 
between fruit 2 and fruit 3; group 3 (exposure to fruit 3), choice tests between fruit 3 and fruit 1 and between fruit 3 and fruit 2 . For each choice test 10 females were used.

The fruits were replaced by other pieces of fruit $(5.0 \mathrm{~g})$ after 24 hours and the experiment was closed after 48 hours. The data were analyzed by the Wilcoxon statistic test at a significance level of 5\% (SIEGEL, 1956).

\section{RESULTS}

The oviposition preference by females for the different tested fruits at the beginning of the oviposition period showed that papaya was the preferred fruit both by the wild and the laboratory females (fig. 1). The second fruit, according to the number of eggs, was the banana, followed by the apple and the orange. Therefore, the hierarchic order of oviposition preference was: papaya $>$ banana $>$ apple $>$ orange (Freedman, $p=0.02$ - lab; $\mathrm{p}=0.0006$ - wild).

The results on the nutritive value of the fruits to the immature (tab. I) showed that both the wild and the laboratory larvae had, in general, a better performance in the papaya and in the banana.

When it was studied the females age influence on the hierarchic change of the oviposition preference for the fruits (fig. 2), it was noted that the results were different from those obtained in the first experiment. It was yet observed that there was a higher oviposition of the wild flies on the papaya, however there was not a statistical difference when all the fruits were compared. The laboratory flies laid more eggs on the banana but, also comparing all fruits, the differences were not statistically significant (Freedman, $\mathrm{p}=0.81-$ lab; $\mathrm{p}=0.37$ - wild).

Based on the results from the previous experiment, the groups of flies, wild and from laboratory, were exposed to one of the three fruits in different hierarchic positions (papaya, banana and orange). The females from the laboratory population previously exposed to the papaya preferred it to the others. The groups of flies from the laboratory population, exposed to either the banana or the orange, did not show a preference to any of these fruits in posterior tests of individual preference (tab. II).
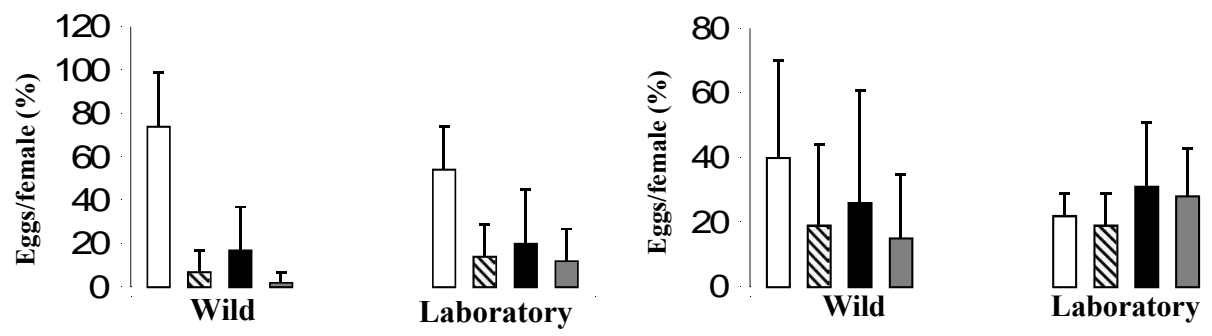

Figs. 1-2. Oviposition preference of laboratory and wild Ceratitis capitata females. 1, at the beginning of oviposition peak; there was statistical difference among all results in both populations (Freedman, $\mathrm{p}=0.02$, laboratory and $\mathrm{p}=0.0006$, wild). 2 , after 20 days of the oviposition peak period; there was no statistical difference between the dates (Freedman, $\mathrm{p}=0.81$, laboratory and $\mathrm{p}=0.37$, wild). Papaya (white), apple (hachured), banana (black), orange (gray). 
Table I. Performance of two Ceratitis capitata populations when fed on 4 different fruits. Means followed by different letters were statistically different $(\mathrm{P}<0.05, \alpha=0.05$, Kruskal-Wallis test).

\begin{tabular}{|c|c|c|c|c|}
\hline \multirow[t]{2}{*}{ Fruits } & \multicolumn{2}{|c|}{ Time to emergence (days) } & \multicolumn{2}{|c|}{ Emergence (\%) } \\
\hline & Laboratory & Wild & Laboratory & Wild \\
\hline Papaya & $16.17 \pm 1.04^{\mathrm{a}}$ & $15.30 \pm 0.26^{\mathrm{a}}$ & $76.67 \pm 5.77^{\mathrm{a}}$ & $87.67 \pm 5.77^{\mathrm{a}}$ \\
\hline Orange & $17.06 \pm 0.06^{\mathrm{a}}$ & $16.76 \pm 1.56^{\mathrm{a}}$ & $24.67 \pm 6.11^{\mathrm{b}}$ & $49.00 \pm 8.54^{\mathrm{b}}$ \\
\hline Banana & $18.20 \pm 0.35^{\mathrm{b}}$ & $16.50 \pm 0.50^{\mathrm{a}}$ & $72.67 \pm 1.15^{\mathrm{a}}$ & $78.33 \pm 7.64^{\mathrm{a}}$ \\
\hline Apple & $17.00 \pm 0.00^{\mathrm{a}}$ & $19.83 \pm 0.76^{\mathrm{b}}$ & $13.33 \pm 5.77^{\mathrm{c}}$ & $16.67 \pm 11.55^{\mathrm{c}}$ \\
\hline
\end{tabular}

Table II. Results of the experiments performed to determine the previous experience influence on oviposition preference of Ceratitis capitata. Percentages followed by different letters (within columns) were statistically different $(\mathrm{P}<0.05, \alpha=0.05$, Wilcoxon test).

\begin{tabular}{llll}
\hline $\begin{array}{l}\text { Previous exposition } \\
\text { (3 days) }\end{array}$ & & $\begin{array}{l}\text { Eggs / female }(\%) \\
\text { Laboratory }\end{array}$ & $\begin{array}{l}\text { Eggs / female (\%) } \\
\text { Wild }\end{array}$ \\
\hline PAPAYA & Papaya & $83 \% \mathrm{a}$ & $85 \% \mathrm{a}$ \\
& Orange & $17 \% \mathrm{~b}(\mathrm{p}=0.0029)$ & $15 \% \mathrm{~b}(\mathrm{p}=0.0019)$ \\
& Papaya & $77 \% \mathrm{a}$ & $87 \% \mathrm{a}$ \\
& Banana & $23 \% \mathrm{~b}(\mathrm{p}=0.0043)$ & $13 \% \mathrm{~b}(\mathrm{p}=0.0012)$ \\
ORANGE & Orange & $60 \% \mathrm{a}$ & $54 \% \mathrm{a}$ \\
& Papaya & $40 \% \mathrm{a}(\mathrm{p}=0.512)$ & $46 \% \mathrm{a}(\mathrm{p}=0.823)$ \\
& Orange & $46 \% \mathrm{a}$ & $67 \% \mathrm{a}$ \\
& Banana & $54 \% \mathrm{a}(\mathrm{p}=0.811)$ & $33 \% \mathrm{a}(\mathrm{p}=0.500)$ \\
BANANA & Banana & $42 \% \mathrm{a}$ & $54 \% \mathrm{a}$ \\
& Papaya & $58 \% \mathrm{a}(\mathrm{p}=0.399)$ & $46 \% \mathrm{a}(\mathrm{p}=0.678)$ \\
& Banana & $67 \% \mathrm{a}$ & $67 \% \mathrm{a}$ \\
& Orange & $33 \% \mathrm{a}(\mathrm{p}=0.250)$ & $33 \% \mathrm{a}(\mathrm{p}=0.960)$ \\
\hline
\end{tabular}

The results on wild flies population were similar to those obtained with the laboratory flies (tab. II). It was observed a preference for the papaya when compared to the others. The groups exposed to the banana and to the orange did not show significant statistical differences in the oviposition preference for the tested fruits.

\section{DISCUSSION}

The present results indicate that: a) the wild and the laboratory females presented a hierarchic preference for the tested fruits in the beginning of the oviposition period, that did not repeat in a later phase of life; b) the exposition of the females to the fruits with lower hierarchic position decreased the intensity of their oviposition preference for the preferred fruit.

The preference hierarchy observed at the beginning of the oviposition peak period could be related to the larval performance, once both the wild and the laboratory larvae had a better performance on the papaya and on the banana. Although having shown a good nutritional value to the larvae, the banana received a lower percentage of eggs than the papaya, especially from the wild population. As the pieces of fruit were offered with their peels and as they are more resistant in the banana, this could have limited the 
number of oviposition on this fruit. Another reason that could explain the low number of oviposition on the banana in relation to the papaya is that, in nature, the banana is not used as a host by $C$. capitata, in contrast to what occurs with the papaya. This fact also demonstrates that this species can physiologically quickly adapt itself to a non-host fruit with proper nutritional value. Therefore, a behavioral change, as the choice of a fruit to oviposition, would be less fast. Physiological changes faster than behavioral changes have already been evidenced for C. capitata (JoACHIM-BRAVo \& Zucoloto, 1998).

The hierarchy of oviposition preference related to the nutritional value of the hosts, as suggested here, does not agree with data obtained previously in experiments of oviposition preference with C. capitata (JoAChim-Bravo \& Zucoloto, 1997a). In those experiments, groups of either 15 wild or laboratory flies were exposed to two fruits with different nutritional values, so that the absence of preference for nutritionally more appropriate fruits to the larvae was observed. The differences between the results obtained previously and those obtained here, where tests were performed with individuals and a preference for a host of better nutritional quality to the larvae was evidenced, can be explained by the change in the methodology approach. It has been discussed in literature that the experiments with groups of flies could conceal a possible genetic variability in preference or could result in a competition for the host, compelling some females to lay on a less preferred fruit (Thompson \& Pellmyr, 1991). Such considerations can be real especially when one works with natural hosts, once the nutritional differences between them, most of the time, are quantitative and not qualitative. Even in oviposition preference tests with groups of flies, when a proper diet or attractive substance is tested against an inert substrate (agar-agar), the flies exhibit a clear preference for the first (JOACHIMBRAVO \& ZuCOLOTO, 1997b).

The experiments with individual $C$. capitata flies generate a difficulty in obtaining the oviposition. Most of the flies die without laying eggs on any host. Such difficulty has been related and discussed in literature where it is shown that, when in groups, the females present a higher stimulus to lay eggs rather than when they are isolated (РROKOPY \& DuAN, 1998).

Comparing the wild and the laboratory population, one generally notes the same hierarchic preference and it is pointed out that probably both laboratory and wild flies had never before gotten in touch with the tested fruits. In spite of being raised for 17 years in laboratory, without the introduction of wild individuals, and usually laying eggs in the holes of the fabric that covers the cage, it is evidenced here that the population exhibited the same hierarchic preference behavior as the wild population. These data might indicate the existence of a strong genetic component that influences such hierarchic behavior on the preference related to the nutritional value of the host.

When the change of hierarchic preference for the fruits associated with the females age was tested, the results showed an absence of hierarchy in the oviposition preference. Despite the absence of preference by the hierarchic lower hosts, there was a higher distribution of eggs through all the hosts, suggesting that the females might have less discrimination in a later than in an earlier phase of life.

These results corroborate the data obtained from other groups of insects, that pointed out an effect of age, among other factors such as foraging time and number of eggs in the ovary, on the increase of preference for the hierarchic inferior hosts (FITT, 
1986, Mangel \& Roitberg, 1989; Courtney et al., 1989; Van Randen \& Roitberg, 1996). According to one of the models on selection patterns by phytophagous insects, reviewed by MAYHEW (1997), the females become, in nature, more able to accept less preferred hosts as they grow old, since it becomes a risk to leave the hierarchic inferior plant without oviposition.

The data obtained in this work suggest that it may have occurred an influence of the previous experience on the posterior choice of lower hierarchy fruits to oviposition by both wild females and laboratory females. This can be evidenced since the papaya (the preferred fruit in other stages of the work) was not chosen when the flies were previously exposed to the orange or the banana. Although there was no inversion in the preference, since there was no difference in the percentage of laid eggs on the different fruits, only the flies that were exposed to the papaya preferred this fruit. However, when only the banana and the orange were compared, the previous experience on one of either fruits had not influenced the posterior choice. This lack of preference for the two fruits should probably result from the strong preference for the papaya by the females, once the number of eggs laid on the papaya was always higher than the number on the banana (second host in the hierarchy). According to some authors, when there is no pronounced hierarchy among the hosts there is always a strong preference for those which the females had a previous contact with. When there is a tendency for the choice of a host over another, if the females had had a previous contact with this other, the preference for the original host continues but decreases in terms of percentage (PHILLIPS, 1977; Cassidy, 1978; Cooley et al., 1986; Papaj \& Prokopy, 1986; Hoffmann, 1988).

Many works have been done to show the importance of different kinds of learning in the choice of diets or fruits to the feeding of the phytophagous insects (TRAYNIER, 1979; PAPAJ \& RAuSher, 1987; PAPAJ \& PROKOPY, 1989). Studies with Rhagoletis pomonella (Walsh), C. capitata and Dacus tryoni (Froggatt) have shown that the previous experience of oviposition on a particular host fruit influences the extension the adults accept or reject either one or another to oviposition (РRокору et al., 1985; PAPAJ \& Próopy, 1986; PROKOPY \& FLETCHER, 1987). The role of learning in the host selection has been thoroughly discussed. In studies with $R$. pomonella and $C$. capitata the learning process was shown to be involved not only in the acceptance of a familiar fruit, but also in the rejection of new fruits. It is postulated that a possible selective advantage of these two kinds of learning is that the females might profit by rejecting the rare hosts if they are able to discriminate between abundant host fruits, thus increasing their reproductive success (Рrokopy et al., 1986; Cooley et al., 1986; Prokopy \& PapaJ, 1988).

In the experiments done here with $C$. capitata, the previous experience on a fruit of hierarchic lower position made easy its posterior acceptance in a confrontation with a more accepted host. Such data corroborate a model discussed by CourTnEy et al. (1989) about the higher acceptance of hosts with lower hierarchic positions after the females had been exposed to them. Such behavior of previous exposure presents the selective advantage to the females of becoming less selective to hosts of lower quality when the preferred hosts are not abundant. To C. capitata such behavior is advantageous, once it makes the females able to find hosts all over the year and, among other factors, it can explain the polyphagous feature of the species.

Acknowledgments. To CNPq for fellowship.

Iheringia, Sér. Zool., Porto Alegre, (91):93-100, 27 de novembro de 2001 


\section{REFERENCES}

CASsidy, M. D. 1978. Development of an induced food plant frequence in the Indian stick insect Carausius morosus. Entomologia exp. appl., Dordrecht, 24:87-93.

Cooley, S. S.; Prokopy, R. J. et al. 1986. Learning in oviposition site selection by Ceratitis capitata flies. Entomologia exp. appl., Dordrecht, 40:47-51.

Courtney, S. P.; Chen, G. K. \& Gardner, A. 1989. A general model for individual host selection. Oikos, Copenhagen, 55:55-65.

Eisemann, C. H. \& Rice, M. J. 1985. Oviposition behaviour of Dacus tryoni: the effects of some sugars and salts. Entomologia exp. appl., Dordrecht, 39:61-71.

FITT, G.P. 1986. The influence of a shortage of hosts on the specificity of oviposition behaviour in species of Dacus (Diptera:Tephritidae). Physiol. Ent., Oxford, 11:133-143.

Hoffmann, A. A. 1988. Early adult experience in Drosophila melanogaster. J. Insect Physiol., Oxford, 34(3): 197-204.

Joachim-Bravo, I. S. \& Zucoloto, F. S. 1997a. Oviposition preference and larval performance in Ceratitis capitata. Revta bras. Zool., Curitiba, 14:795-802.

1997b. Oviposition preference in Ceratitis capitata (Diptera, Tephritidae): influence of rearing diet. Iheringia, Sér. Zool., Porto Alegre, (82):133-140.

1998. Performance and feeding behavior of Ceratitis capitata: comparison of a wild population and laboratory population. Entomologia exp. appl., Dordrecht, 87:67-72.

KostaL, V. 1993. Physical and chemical factors influencing landing and oviposition by the cabbage root fly on host-plant models. Entomologia exp. appl., Dordrecht, 66:109-118.

Malavasi, A.; Morganti, J. S. \& Zucchi, R. A. 1980. Biologia de "moscas-das-frutas". I. Lista de hospedeiros e ocorrência. Revta bras. Biol., Rio de Janeiro, 40(1):9-16.

Mangel, M. \& Rortberg, B. D. 1989. Dynamic information and host acceptance by a tephritid fruit fly. Ecol. Ent., London, 14:181-189.

Martins, D. S.; Alves, F. L. \& Zucchi, R. A. 1993. Levantamento de moscas-das-frutas (Diptera: Tephritidae) na cultura do mamoeiro (Carica papaya L.) no norte do estado do Espírito Santo. Anais Soc. ent. Bras., Londrina, 22(2):373-379.

MaYhew, P. J. 1997. Adaptive patterns of host-plant selection by phytophagous insects. Oikos, Copenhagen, 79:417-428.

McInNIs, D. O. 1989. Artificial oviposition sphere for Mediterranean fruit flies (Diptera: Teprhitidae) in field cages. J. econ. Ent., Lanham, 82(5):1382-1385.

Messina, F. J. 1990. Components of host choice by two Rhagoletis species (Diptera: Tephritidae) in Utah. J. Kans. ent. Soc., Lawrence, 63(1):80-87.

OI, D. H. \& MAU, R. F. L. 1989. Relationship of fruit ripeness to infestation in "Sharwil" avocados by the mediterranean fruit fly and oriental fruit fly (Diptera: Tephritidae). J. econ. Ent., Lanham, 82(2): 556-560.

PAPAJ, D. R. \& PRokopy, R. J. 1986. Phytochemical basis of learning in Rhagoletis pomonella and other herbivorous insects. J. Chem. Ecol., New York, 12(5):1125-1143.

1989. Ecological and evolutionary aspects of learning in phytophagous insects. A. Rev. Ent., Palo Alto, 34:315-350.

PAPAJ, D. R. \& RAUSHER, M. D. 1987. Components of consespecific host plant discrimination by Battus philenor (Papilionidae). Ecology, Washington DC, 68:245-253.

PhiLLIPS, W. M. 1977. Modification of feeding preference in the flea-beetle, H. lythri. Entomologia exp. appl., Dordrecht, 21:71-80.

Prokopy, R. J.; Aluja, M. et al. 1989. Influence of previous experience with host plant foliage on behavior of Mediterranean fruit fly females. Proc. Hawaii. ent. Soc., Honolulu, 29:97-101.

Prokopy, R. J. \& Duan J. J. 1998. Socially facilitated egglaying behavior in Mediterranean fruit flies. Behav. Ecol. Sociobiol., Heidelberg, 42 (2):117-122.

PRóopy, R. J. \& FletcheR, B. S. 1987. The role of adult learning in the acceptance of host fruit for egglaying by the Queensland fruit fly, Dacus tryoni. Entomologia exp. appl., Dordrecht, 45:259-263.

Prokopy, R. J.; Kallet, C. \& Cooley, S. S. 1985. Fruit acceptance pattern of Rhagoletis pomonella flies from different geographic regions. Ann. ent. Soc. Am., Lanham, 78:799-803.

Prokopy, R. J. \& PAPAJ, D. R 1988. Learning of apple fruit biotypes by apple maggot flies. J. Insect Behav., New York, 1(1):67-74.

PROKOPY, R. J.; PAPAJ, D. R. et al. 1986. On the nature of learning in oviposition site acceptance by apple maggot 
flies. Anim. Behav., London, 34:98-107.

Prokopy, R. J. \& Roitberg, B. D. 1984. Foraging behavior of true fruit flies. Am. Scient., New Haven, 72:39-49.

Renwick, J. A. A. 1989. Chemical ecology of oviposition in phytophagous insects. Experientia, Barel, 45:223-228.

Siegel, S. 1956. Nonparametric Statistics for the Behavioral Sciences, New York, MacGraw-Hill. 340 p.

SINGER, M.C. 1986. The definition and measurement of oviposition preference in plant-feeding insects. In:MILLER J. R. \& MiLLER, T. A. ed. Insect-plant interactions, New York, Springer-Verlag. p. 66-94.

Thompson, J. N. 1988. Evolutionary ecology of the relationship between oviposition preference and performance of offspring in phytophagous insects. Entomologia exp. appl., Dordrecht, 47:3-14.

Thompson, J. N. \& Pellmyr, O. 1991. Evolution of oviposition behavior and host preference in Lepidoptera. A. Rev. Ent., Palo Alto, 36:65-89.

TRAYNIER, R. M. M. 1979. Associative learning in the oviposition behavior of the cabbage butterfly, Pieris rapae. Entomologia exp. appl., Dordrecht, 9:465-472.

VAn RANDEn, E. \& RoitBerg, B. D. 1996. The effect of egg load on superparasitism by the snowberry fly. Entomologia exp. appl., Dordrecht, 79:241-245.

ZucoLoto, F. S. 1993. Acceptability of different Brazilian fruits to Ceratitis capitata (Diptera, Tephritidae) and fly performance on each species. Braz. J. Med. Biol. Res., Ribeirão Preto, 26: 291-298.

Recebido em 31.08.2000; aceito em 30.05.2001 